\title{
Harm aversion explains utilitarian choices in moral decision-making in males but not in females
}

\author{
G. ROTA', S. PALUMBO², N. LATTANZI ${ }^{3}$, A. MANFRINATI ${ }^{4}$, M. SARLO 5 , L. LOTTO, \\ P. PIETRINI' , R. RUMIATI6, S. PELLEGRINI ${ }^{8}$ \\ ${ }^{1}$ Clinical Psychology Branch, Azienda Ospedaliero-Universitaria Pisana, Pisa, Italy; ${ }^{2}$ Department of \\ Surgical, Medical, Molecular Pathology and Critical Care, University of Pisa, Pisa, Italy; ${ }^{3}$ Department \\ of Economics and Management, University of Pisa, Pisa, Italy; ${ }^{4}$ Department of Psychology, University \\ of Milano-Bicocca, Milano, Italy; ${ }^{5}$ Department of General Psychology and Center for Cognitive \\ Neuroscience, University of Padova, Padova, Italy; ${ }^{6}$ Department of Developmental Psychology \\ and Socialization and Center for Cognitive Neuroscience, University of Padova, Padova, Italy; 7 IMT \\ School for Advanced Studies, Lucca, Italy; ${ }^{8}$ Department of Clinical and Experimental Medicine, \\ University of Pisa, Pisa, Italy
}

\section{A B S T R A C T}

In recent years, a great deal of research has relied on hypothetical sacrificial dilemmas to investigate decision-making processes involved in pro-social utilitarian choices. Recent evidence, however, has suggested that moral sacrificial choices may actually reflect reduced harm aversion and antisocial dispositions rather than an utilitarian inclination. Here, we used moral dilemmas to confront healthy volunteers with controversial action choices. We measured impulsiveness and venturesomeness personality traits, which have been shown to influence harm aversion, to test their role in utilitarian action and evaluation of moral acceptability.

The results of the present study show that, in males, venturesomeness drives engagement in actions and increases moral acceptability. In contrast, in females no effects of venturesomeness were observed on moral action and evaluation. Rather, in females empathetic concern and personal distress, elicited by the vicarious experience of the other's emotional states, exerted an inhibitory effect on action. Taken together, these findings indicate that the "harm aversion hypothesis" may contribute to explain utilitarian choices in males but not in females. In both genders, no association was observed between impulsiveness and moral action.

Key words

Moral judgments $\bullet$ Harm aversion $\bullet$ Utilitarian choices $\bullet$ Impulsiveness $\bullet$ Venturesomeness

\section{Introduction}

Classical utilitarianism poses that humans should aim at maximizing the greater good of society as a whole (Bentham, 1789, 1961). This philosophical perspective promotes the idea that one should give no special priority to his/her own interests as compared to the aim of increasing the collective welfare.

Typically, decision-making processes that lead to utilitarian actions have been investigated by means of hypothetical moral dilemmas. In these paradigms, written scripts are used to present volunteers with action alternatives, in which they are required to sacrifice the life of one person in order to favor the survival of many other individuals. These paradigms have been employed as prototypical examples of utilitarian actions in a great deal of researches (e.g., Greene et al., 2008).

A recent study by Kahane and colleagues (2015) called into question this assumption. The authors 
demonstrated that responses to sacrificial dilemmas are not "utilitarian" sensu strictu, i.e., they do not embody the concern of achieving a greater aggregate good, but rather reflect a lower aversion to harming others. More specifically, the authors showed that "utilitarian" judgments are associated to trait psychopathy, reduced empathetic concern, as well as to measures of amoral disposition in business contexts and lack of pro-social dispositions.

In the present study, to determine whether "utilitarian" responses in sacrificial dilemmas are driven by a greater concern for the aggregate welfare or rather reflect reduced aversion to harmful actions, we set out to tackle the role of impulsiveness and venturesomeness - two features that closely reflect harm avoidance - in moral actions.

Impulsive behaviors have been defined as "hasty actions that occur in the moment without forethought and that have high potential for harm to the individual" (American Psychiatric Association, 2013). Impulsiveness leads to actions that take place rapidly, prematurely, and with no careful evaluation of their potential consequences. Moreover, impulsiveness has been associated to poor self-control and to the inability to delay gratification over time (Monterosso \& Ainslie, 1999), as well as to a reduced sensitivity to negative consequences (Moeller et al., 2001).

Eysenck \& Eysenck (1978) introduced the construct of "venturesomeness" to capture adventurous and risk-taking behavior as well as quick decisionmaking processes. Specifically, this construct captures sensation-seeking behavior in individuals that are well aware of the risks they undertake.

Aversion to harmful actions is reduced in individuals who exhibit great impulsive behavior, including drug abusers and psychopaths (Morgan et al., 2011; Zhao et al., 2015). Consistently, impulsiveness and poor volitional control have been linked to aggressive behavior (e.g., Pietrini \& Bambini, 2009; Rigoni et al, 2010; Scarpa and Raine, 1997; Sartori et al, 2011; Iofrida et al, 2014; Coccaro et al., 2015). High levels of venturesomeness and sensation seeking, moreover, are linked to a reduced concern for the potentially negative - life threatening - consequences associated to risktaking behavior (e.g., Zuckerman, 2007). Scientific evidence has shown that males engage more often in risky activities, suggesting a gender-differential effect as far as sensation seeking behavior is concerned (e.g.,
Cross et al., 2013). Also, moral decision-making and judgment appear to be strongly influenced by gender (see for instance Scheele et al., 2014), as females typically exhibit a lower frequency of utilitarian responses than males (Fumagalli et al., 2010).

In the present study, we tested the hypothesis that high levels of impulsiveness and venturesomeness would increase utilitarian decisions. Because both high impulsiveness and venturesomeness are closely associated with reduced aversion to harm, we reasoned that their association with "utilitarian" choices would lead support to the "reduced harm aversion" hypothesis. Finally, we predicted genderrelated effects on both venturesomeness and utilitarian responses.

\section{Methods}

\section{Participants}

Two hundred Caucasian volunteers (98 males and 102 females), with no history of neurological and/ or psychiatric disorders, aged between 18 and 35 years, were recruited among the students of the University of Pisa and University of Padua, in Italy. Sample size was determined on the basis of prior literature on moral dilemmas (e.g. Moore et al., 2008). The study was conducted under a research protocol approved by Local Ethic Committees at both Universities. After signing a written informed consent, participants were asked to respond to a set of moral dilemmas.

\section{Materials}

Fifty-six written moral dilemmas, characterized by two types of scenarios (as in Lotto et al., 2014) were used: 28 incidental dilemmas (i.e., the sacrifice of one person to save more people is a foreseen but unintended side-effect of action $=\mathrm{SE}$ scenarios) and 28 instrumental dilemmas (i.e., the sacrifice of one person is the mean to save more people = $\mathrm{M}$ scenarios). Within these two groups, dilemmas were differentiated on the basis of the personal involvement for the responders themselves: that is, in 14 dilemmas for each group, killing one individual allowed responders to save themselves besides other people (self-involvement dilemmas $=$ SI scenarios), whereas, in the remaining 14 dilemmas, killing one individual resulted in saving other people only 
(no-involvement dilemmas $=$ NI scenarios). Finally, life expectancy of people to be sacrificed was also manipulated: in half of the dilemmas, subjects were healthy (normal life expectancy dilemmas $=$ $\mathrm{N}$ scenarios), whereas, in the other half, they were severely injured or terminally ill patients (reduced life expectancy dilemmas $=\mathrm{R}$ scenarios).

\section{Procedure}

Dilemmas were presented as written strings of text on a computer screen. Each dilemma described a short story that contained a moral conflict, and proposed to endorse a specific action to solve it. Participants were instructed to read each dilemma at their own pace and then to express their willingness (Yes/No) to engage in the proposed action by pressing a computer key. Yes/ No labels for response buttons were located either on the left or on the right of the computer keyboard in a balanced randomized manner across participants. We recorded the frequency of Yes answers (Freq_Y), that is the frequency of utilitarian solution selection. Furthermore, subjects were asked to evaluate moral acceptability (Acceptability) of the proposed actions by using an 8 -point scale $(0=$ not acceptable at all, 7 = completely acceptable). Finally, the degree of Valence $(1=$ very unpleasant, $9=$ very pleasant $)$ and Arousal $(1=$ not at all, $9=$ very much) associated to each proposed action were evaluated by using the Self Assessment Manikin scales (Bradley and Lang, 1994).

\section{Psychological scales}

All subjects underwent an evaluation of personality traits and mood state. Specifically, volunteers completed the Impulsiveness-VenturesomenessEmpathy Questionnaire (I7) (Russo et al., 2011). We took into consideration for the analysis the following subscales of I7: Venturesomeness (V) and Impulsiveness (I). Also, they were required to fill out the Interpersonal Reactivity Index (IRI) (Davis, 1980), which includes the following subscales: Fantasy (F), Perspective Taking (PT), Empathetic Concern (EC) and Personal Distress (PD).

Finally, each participant was asked to fill out the Profile of Mood States questionnaire (POMS) (McNair et al., 1971). The POMS includes the following subscales: Tension-Anxiety (TA), Depression-Dejection (DD), Anger-Hostility (AH), Vigor-Activity (VA), Fatigue-Inertia (FI) and Confusion-Bewilderment (CB).

\section{Statistical analysis}

SPSS Advanced Statistic v21 (IBM Corporation, Armonk, NY, USA) was used for statistical analysis. Data deviation from normality was evaluated by Kolmogorov-Smirnov and Shapiro-Wilks tests. Outlier elimination (below the $5^{\text {th }}$ and above the $95^{\text {th }}$ percentiles) was applied to obtain normalized data distributions.

Association analyses between dependent variables obtained from dilemmas (Freq_Y, Acceptability, Arousal and Valence) and behavioral scales (IRI, I7 and POMS), type of dilemma (M, SE, R, N, SI, NI) and gender were performed by Generalized Estimating Equations (GEEs). Loglinear Poisson distributions were used to analyze the Freq_Y variable, while Tweedie distributions with identity link function were used to analyze the other variables. An exchangeable working correlation matrix resulted to be the most suitable method to model within-subject dependency. To assess gender differences in impulsiveness, empathy and affective state we applied a univariate analysis of variance-covariance (ANOVAANCOVA).

Bonferroni adjustments for multiple comparisons were used to correct for type I error rate of post-hoc tests. To assess correlations among psychological scores we calculated the Spearman's rank correlation coefficient (@).

\section{Results}

\section{Utilitarian responses (Freq_Y)}

In the whole group (both males and females), Freq_Y was significantly higher in SE, R and SI scenarios as compared to their counterparts $(\mathrm{SE}>\mathrm{M}$ : Wald chisquare test $=294.042, \mathrm{df}=1, \mathrm{p}=10^{-7} ; \mathrm{R}>\mathrm{N}$ : Wald chisquare test $=195.315, \mathrm{df}=1, \mathrm{p}=10^{-7}$; $\mathrm{SI}>\mathrm{NI}$ : Wald chisquare test $=27.000, \mathrm{df}=1, \mathrm{p}=10^{-7}$ ) (Fig. 1a). Significant results were observed also when the two genders were considered separately (SE $>$ M: Wald chi-square test $=319.636, \mathrm{df}=2, \mathrm{p}=10^{-7}$, Females $\mathrm{p}=10^{-7}$, Males $\mathrm{p}=10^{-7} ; \mathrm{R}>\mathrm{N}$ : Wald chi-square test $=188.380, \mathrm{df}=2$, $\mathrm{p}=10^{-7}$, Females $\mathrm{p}=10^{-7}$, Males $\mathrm{p}=10^{-7}$; SI $>\mathrm{NI}$ : Wald chi-square test $=25.029, \mathrm{df}=2, \mathrm{p}=4 \times 10^{-6}$, Females $\mathrm{p}=0.003$, Males $\left.\mathrm{p}=5.8 \times 10^{-5}\right)$ (Fig. 1b).

Overall, utilitarian responses were significantly more frequent in males as compared to females (Wald chisquare test $=15.039, \mathrm{df}=1, \mathrm{p}=10^{-4}$ ) (Fig. 1c). 


\section{Moral acceptability}

In the whole group, Acceptability was significantly higher in SE and NI scenarios as compared to their counterparts (SE $>$ M: Wald chi-square test $=20.235$, $\mathrm{df}=1, \mathrm{p}=7 \times 10^{-6}$; NI $>\mathrm{SI}$ : Wald chi-square test $=7.086$, $\mathrm{df}=1, \mathrm{p}=0.008$ ) (Fig. 1d). Both genders rated SE scenarios as more acceptable than their counterparts (SE $>\mathrm{M}$ : Wald chi-square test $=20.858, \mathrm{df}=2, \mathrm{p}=3 \times 10^{-5}$, Females $p=0.008$, Males $p=0.004$ ) (Fig. 1e). Females also rated NI scenarios as more acceptable than their counterparts (NI $>$ SI: Wald chi-square test $=11.526$, $\mathrm{df}=2, \mathrm{p}=0.003$, Females $\mathrm{p}=0.008$, Males $\mathrm{p}=1$ ) (Fig. 1e). Overall, males judged actions as significantly more acceptable than females (Wald chi-square test $\left.=23.302, \mathrm{df}=1, \mathrm{p}=2 \times 10^{-6}\right)$ (Fig. 1f).

\section{Valence and Arousal Ratings}

In the whole group, engagement in the proposed action in the $\mathrm{N}$ scenarios was rated as significantly less unpleasant then their counterparts $(\mathrm{N}>\mathrm{R}$ : Wald chi-square test $=6.134$, $\mathrm{df}=1, \mathrm{p}=0.013$ ) (Fig. 1g). Such a difference was not observed in each gender separately (Fig. 1h).

Overall, males rated engagement in the proposed actions as significantly less unpleasant than females (Wald chisquare test=17.271, $\mathrm{df}=1, \mathrm{p}=3.4 \times 10^{-5}$ ) (Fig. 1i). In the whole group, Arousal was higher in SI scenarios as compared to their counterparts (SI>NI: Wald chisquare test $=32.936, \mathrm{df}=1, \mathrm{p}=10^{-7}$ ) (Fig. $1 \mathrm{j}$ ). This result remained significant when the analysis was conducted in each gender separately (SI>NI: Wald chi-square test $=33.857, \mathrm{df}=2, \mathrm{p}=10^{-7}$, Females $\mathrm{p}=0.001$, Males $\mathrm{p}=7.2 \times 10^{-5}$ ) (Fig. 1k). No differences in Arousal were detected between genders (Fig. 11).

\section{Behavioral Scales}

\section{Impulsiveness and Venturesomeness}

Females had significantly higher levels of I7 Impulsiveness than males $\left(\mathrm{F}_{(1,196)}=4.846, \mathrm{MSE}=59.623\right.$, $\mathrm{p}=0.029)$, whereas males showed significantly higher scores of I7_Venturesomeness than females $\left(F_{(1,196)}=13.468, M S E=144.013, p=3.1 \times 10^{-4}\right)$ (Fig. 2a).

\section{Empathy and Affective States}

Females revealed significantly higher IRI Total scores than males $\left(\mathrm{F}_{(1,194)}=12.761, \mathrm{MSE}=362.217, \mathrm{p}=4.5 \times 10^{-}\right.$ ${ }^{4}$ ) (Fig. 2b), as well as higher scores in all the IRI subscales, with the only exception of IRI_PT (IRI_F: $\mathrm{F}_{(1,194)}=8.433, \mathrm{MSE}=386.124, \mathrm{p}=0.004$; IRI_EC: $\mathrm{F}_{(1,194)}=13.069, \mathrm{MSE}=350.324, \mathrm{p}=3.8 \times 10^{-4}$; IRI_PD: $\mathrm{F}_{(1,194)}=23.606, \mathrm{MSE}=889.146, \mathrm{p}=2 \times 10^{-6}$ ) (Fig. 2c). Females showed also significantly higher POMS TA scores than males $\left(\mathrm{F}_{(1,194)}=4.583, \mathrm{MSE}=201.637\right.$, $\mathrm{p}=0.034)$ (Fig. 2d).

\section{Correlation between response variables to dilemmas and psychological scores}

\section{Utilitarian responses (Freq_Y)}

Impulsiveness and Venturesomeness. Freq_Y positively correlated with I7_Venturesomeness in the whole group (Wald chi-square test $=10.580$, $\mathrm{df}=1, \mathrm{p}=0.001$ ) and in males (Wald chi-square test $=8.561, \mathrm{df}=2, \mathrm{p}=0.014$ : Males $\mathrm{p}=0.008$, Females $\mathrm{p}=0.766$ ).

Empathy. Freq_Y positively correlated with IRI_Fantasy in the whole group (Wald chi-square test $\left.=14.614, \mathrm{df}=1, \mathrm{p}=1.3 \times 10^{-4}\right)$, and in each gender separately (Wald chi-square test $=18.049, \mathrm{df}=2$, $\mathrm{p}=1.2 \times 10^{-4}$ : Males $\mathrm{p}=8.3 \times 10^{-4}$, Females $\mathrm{p}=0.038$ ). Furthermore, Freq_Y negatively correlated with IRI_Empathetic Concern in the whole group (Wald chi-square test $=9.455, \mathrm{df}=1, \mathrm{p}=0.002$ ) and in females (Wald chi-square test $=9.170, \mathrm{df}=2, \mathrm{p}=0.010$ : Males $\mathrm{p}=1$, Females $\mathrm{p}=0.008$ ).

Affective states. Freq_Y negatively correlated with POMS_Tension-Anxiety in the whole group (Wald chi-square test $=6.286, \mathrm{df}=1, \mathrm{p}=0.012$ ), and positively correlated with POMS_Vigor-Activity, both in the whole group (Wald chi-square test $=14.783$, $\mathrm{df}=1, \mathrm{p}=1.2 \times 10^{-4}$ ) and in males (Wald chi-square test $=27.709, \mathrm{df}=2, \mathrm{p}=10^{-6}$ : Males $\mathrm{p}=10^{-7}$, Females $\mathrm{p}=0.230$ ).

\section{Acceptability}

Impulsiveness and Venturesomeness. Acceptability positively correlated with I7_Venturesomeness in the whole group (Wald chi-square test $=4.774, \mathrm{df}=1$, $\mathrm{p}=0.029$ ) and in males (Wald chi-square test $=7.289$ $\mathrm{df}=2, \mathrm{p}=0.026$ : Males $\mathrm{p}=0.044$, Females $\mathrm{p}=0.73$ ).

Empathy. Acceptability negatively correlated with the IRI Total in the whole group (Wald chi-square test $=17.846, \mathrm{df}=1, \mathrm{p}=2.4 \times 10^{-5}$ ) and in each gender separately (Wald chi-square test $=20.867 \mathrm{df}=2$, $\mathrm{p}=2.9 \times 10^{-5}$ : Males $\mathrm{p}=0.04$, Females $\mathrm{p}=3.3 \times 10^{-4}$ ). 

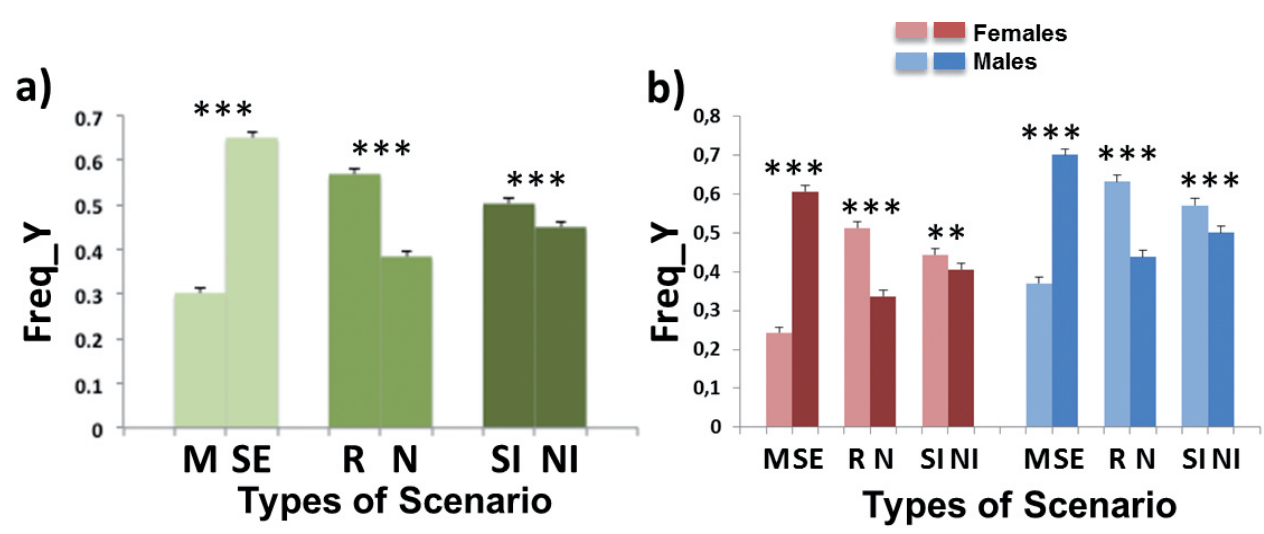

c)

d)

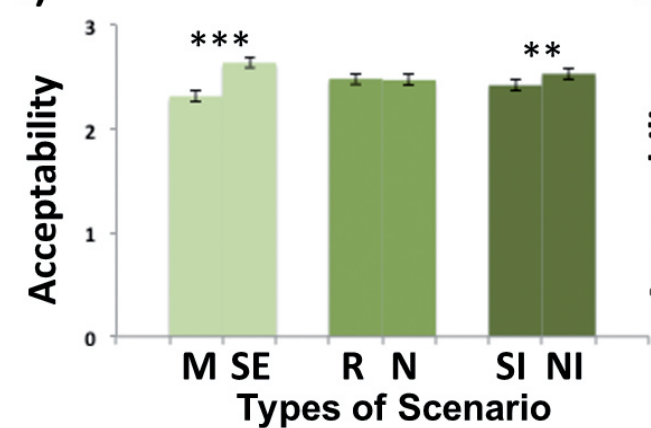

g)

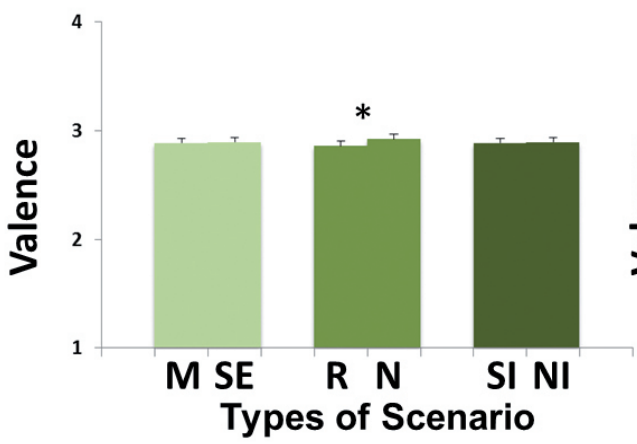

e)

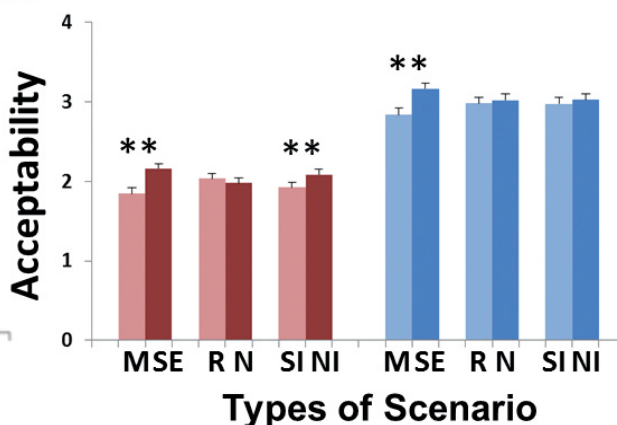

h)

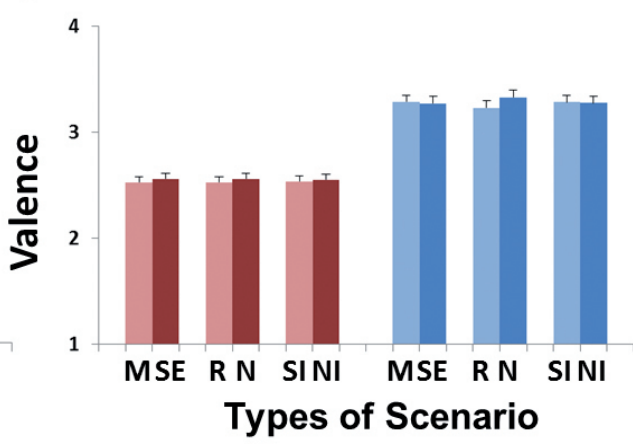

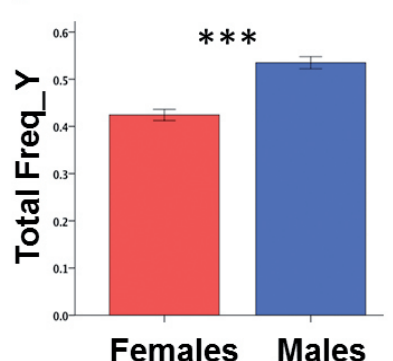

f)

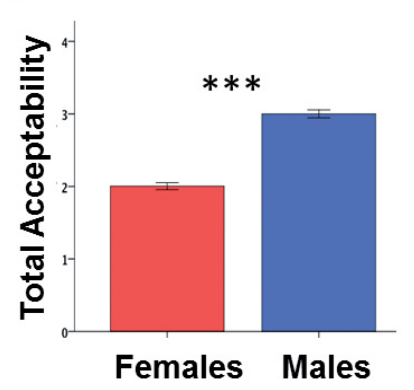

i)

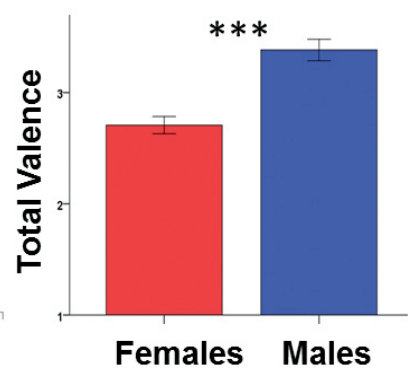

j)

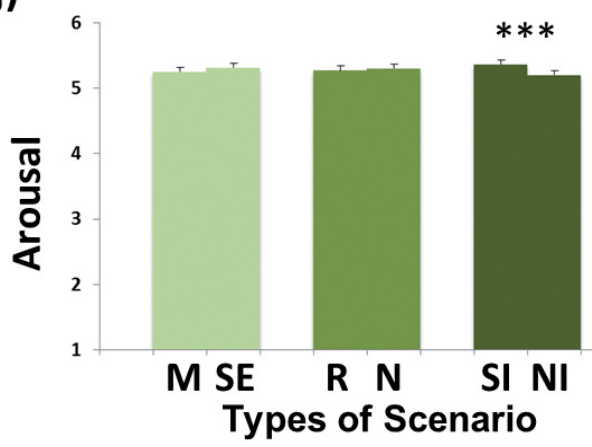

k)

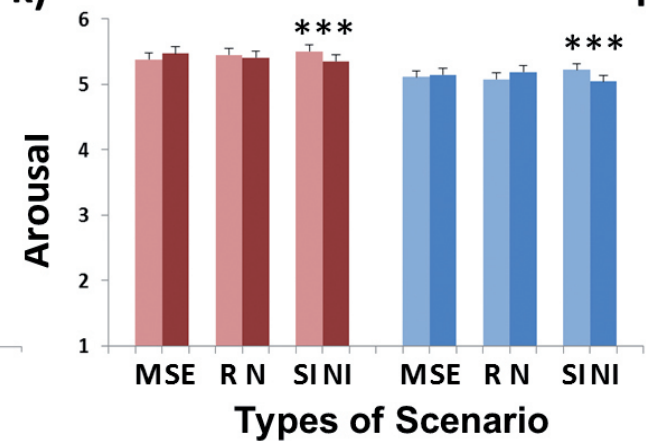

I)

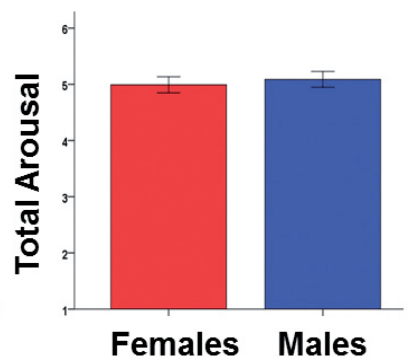

Fig. 1. - Rates of Freq_Y, Acceptability, Valence and Arousal. Freq_Y in the six different types of scenario as compared to their counterparts: a) in the whole group and b) in each gender; c) gender differences in total Freq_Y. Acceptability in the six different types of scenario as compared to their counterparts: $d$ ) in the whole group and e) in each gender; f) gender differences in total Acceptability. Valence in the six different types of scenario as compared to their counterparts: g) in the whole sample and h) in each gender; i) gender differences in total Valence. Arousal in the six different types of scenario as compared to their counterparts: $j$ ) in the whole group and $k$ ) in each gender; I) gender differences in total Arousal. Bars represent mean \pm SEM. ${ }^{*}=\mathrm{p} \leq 0.05,{ }^{* *}=\mathrm{p} \leq 0.01,{ }^{* * *}=\mathrm{p} \leq 0.001$. Abbreviations: $\mathrm{M}=\mathrm{means}, \mathrm{SE}=$ side effect, $\mathrm{R}=$ reduced life expectancy, $\mathrm{N}$ = normal life expectancy, $\mathrm{SI}=$ self-involvement, $\mathrm{NI}=$ non-involvement. 
It also negatively correlated with IRI_Empathetic Concern in the whole group (Wald chi-square test $=20.069, \mathrm{df}=1, \mathrm{p}=7 \times 10^{-7}$ ) and in females (Wald chi-square test $=35.753, \mathrm{df}=2, \mathrm{p}=10^{-7}$ : Males $\mathrm{p}=1$, Females $\mathrm{p}=10^{-7}$ ).

Affective States. Acceptability negatively correlated with POMS_Tension-Anxiety (Wald chi-square test $=11.926$, $\mathrm{df}=1, \mathrm{p}=5.5 \times 10^{-4}$ ) and positively correlated with POMS Fatigue-Inertia (Wald chi-square test $=7.006, \mathrm{df}=1$, $\mathrm{p}=0.008$ ) in the whole group only.

\section{Valence}

Impulsiveness and Venturesomeness. Valence positively correlated with I7_Impulsiveness in the whole group (Wald chi-square test $=4.241, \mathrm{df}=1$, $\mathrm{p}=0.039$ ) and in males (Wald chi-square test $=10.122$, $\mathrm{df}=2, \mathrm{p}=0.006$ : Males $\mathrm{p}=0.002$, Females $\mathrm{p}=0.908$ ).

Empathy. Valence negatively correlated with IRI Total in the whole group (Wald chi-square test $=11.735, \mathrm{df}=1, \mathrm{p}=0.001$ ) and in females (Wald chi-square test $=23.626, \mathrm{df}=2, \mathrm{p}=5 \times 10^{-7}$ : Males $\mathrm{p}=0.422$, Females $\mathrm{p}=0.002$ ). It also negatively correlated with IRI_Empathetic Concern in the whole group (Wald chi-square test $=31.437, \mathrm{df}=2$, $\mathrm{p}=10^{-7}$ ) and in both genders separately (Wald chisquare test $=42.468, \mathrm{df}=2, \mathrm{p}=0.001$ : Males $\mathrm{p}=0.024$, Females $\mathrm{p}=10^{-7}$ ).

Affective States. Valence negatively correlated with POMS_Tension-Anxiety (Wald chi-square test $=11.926, \mathrm{df}=1, \mathrm{p}=7 \times 10^{-4}$ ) and positively correlated with POMS_Fatigue-Inertia (Wald chisquare test $=4.432, \mathrm{df}=1, \mathrm{p}=0.035$ ) in the whole group only.

\section{Arousal}

Empathy. Arousal negatively correlated with IRI_Fantasy in females only (Wald chi-square test $=8.151, \mathrm{df}=2, \mathrm{p}=0.017$ : Males $\mathrm{p}=0.592$, Females $\mathrm{p}=0.016$ ). It also positively correlated with IRI Empathetic Concern (Wald chi-square test $=3.976$, $\mathrm{df}=1, \mathrm{p}=0.046)$ and negatively correlated with IRI_ Personal Distress in the whole group (Wald chisquare test $=5.447, \mathrm{df}=1, \mathrm{p}=0.02$ ).

\section{Correlation between behavioral scales}

I7_Impulsiveness negatively correlated with IRI_ Perspective Taking $\left(\varrho=-0.265, \mathrm{p}=4.4 \times 10^{-4}\right)$ and POMS_Vigor-Activity $(\varrho=-0.202, \mathrm{p}=0.004)$. It positively correlated with POMS_Tension-Anxiety $\left(\varrho=0.432, \quad p=10^{-7}\right), \quad$ POMS_Depression-Dejection $\left(\mathrm{Q}=0.335, \quad \mathrm{p}=3.1 \times 10^{-4}\right), \quad$ POMS_Anger-Hostility $\left(\mathrm{Q}=0.382, \mathrm{p}=10^{-6}\right)$, POMS_Fatigue-Inertia $(\mathrm{Q}=0.337$, $\left.\mathrm{p}=1.5 \times 10^{-5}\right)$, and POMS_Confusion-Bewilderment $\left(\mathrm{Q}=0.269, \mathrm{p}=1.7 \times 10^{-4}\right)$.

I7_Venturesomeness positively correlated with IRI_ Fantasy $(\varrho=0.151, p=0.032)$ and negatively correlated with IRI_Personal Distress ( $\mathrm{Q}=-0.187, \mathrm{p}=0.009)$.

\section{Discussion}

The results of the present study indicate that when confronted with moral dilemmas, participants were more willing to sacrifice another person when their own life was at stake, though they considered this behavior not morally acceptable. Moreover, they opted more often to sacrifice a person when the individual had a short life expectancy. Finally, they behaved in a more utilitarian manner and valued as more acceptable the sacrifice of a person when this was a side effect of an action aimed at achieving a greater good than when the person's death was instrumental to reach the goal. Taken together, these findings are in line with results from previous studies on moral choices (e.g., Lotto et al., 2014; Moore et al., 2008).

While so far most research on moral judgment has relied on sacrificial dilemmas, recent evidence has called into question the suitability of those paradigms in addressing genuine utilitarian choices, that is, choices that aim at achieving a greater societal good. Kahane and colleagues (2015) have claimed that the so-called "utilitarian actions", investigated by the means of sacrificial dilemmas, may rather reflect reduced harm aversion.

In order to address this controversial issue, here we investigated whether impulsiveness and venturesomeness, which are psychological traits associated with harm aversion, may influence utilitarian responses, and whether such a potential effect differs between males and females.

Previous studies have shown gender effects in moral evaluation and decision-making. For instance, Fumagalli and coworkers (2010) found that males show a higher frequency of utilitarian responses in moral personal dilemmas. These authors linked gender specific effects in moral tasks to differences in empathetic capacity, as typically males score poorer in empathy-related questionnaires. 
a)

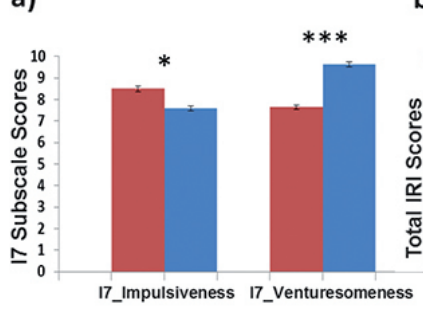

b)

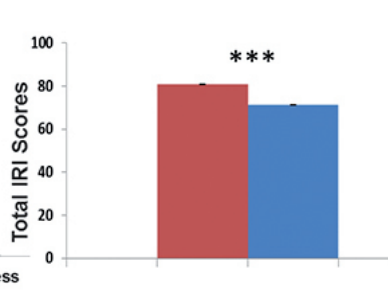

c)

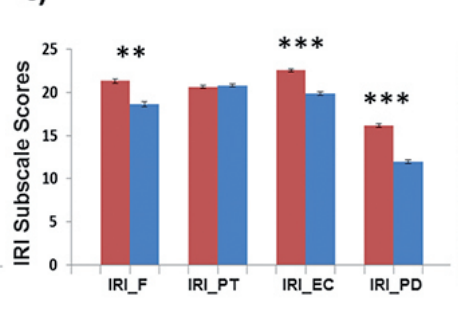

d)

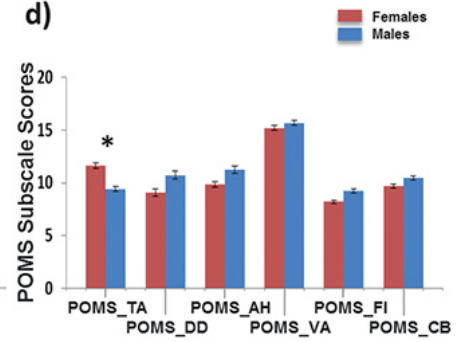

Fig. 2. - Gender difference in impulsiveness, empathy and mood scales. a) I7 subscale scores, b) IRI Total scores, c) IRI subscale scores and d) POMS subscale scores in the two genders. Bars represent mean $\pm \mathrm{SEM}$. ${ }^{*}=\mathrm{p} \leq 0.05$, $*^{*}=\mathrm{P} \leq 0.01,{ }^{* * *}=\mathrm{p} \leq 0.001$. Abbreviations: IRI_F = Fantasy; IRI_PT = Perspective Taking; IRI_EC = Empathetic Concern; IRI_PD = Personal Distress; POMS_TA = Tension Anxiety; POMS_DD = Depression-Dejection; POMS_AH = Anger-Hostility; POMS_VA = Vigor-Activity; POMS_FI = Fatigue-Inertia, POMS_CB = Confusion-Bewilderment.

Our results indicate that males, as compared to females, endorse utilitarian actions more frequently and consider these choices less aversive and far more acceptable. Interestingly, this pattern of responses was consistent across all types of scenarios. Thus, this behavioral finding reflects a higher disposition toward action in males. Consistently, males displayed higher levels of venturesomeness, which correlated with their rate of utilitarian actions as well as with their level of acceptability of the proposed actions. Finally, POMS scores of VigorActivity, reflecting a mood of vigorousness and high energy, and scores of IRI-Fantasy, reflecting empathy for fictional characters, also correlated with the rate of utilitarian choices. Taken together, these results show that, in males only, individual disposition to risky behavior, as well as vigoractivity emotional states, facilitate action, thus increasing their engagement in utilitarian choices. This finding is consistent with the hypothesis that reduced harm aversion may account for the engagement in action in sacrificial dilemmas. Importantly, our results extend previous data by demonstrating that this effect applies to males only. Scientific evidence has shown gender-differential effects regarding sensation-seeking behavior. A number of studies, for example, have shown higher death rates for unnatural causes, such as falls, firearm accidents and drowning in males as compared to females (e.g., Pampel, 2001). Consistently, driving style of men appears to be markedly more reckless, and the number of fatalities due to car accidents is significantly higher in males than in females (Beattie, 2008). Finally, men engage more often in fights and violent aggression as compared to women (Beattie, 2008).
Sensation-seeking behavior in males has been linked to hormonal function and, specifically, to the effect of testosterone on cognition and emotion (Aluja \& Torrubia, 2004). Aluja and Torrubia, for example, reported a correlation between high scores in personality traits linked to sensation seeking - including experience seeking, disinhibition and boredom susceptibility - and testosterone levels. Thus, the effects of sex hormones in males may account for their greater engagement in action observed in the present study.

In females, we observed higher scores of impulsiveness as compared to males. This trend has already been reported in the literature (Russo et al., 2011), and was presumably more pronounced in our sample due to the young age of our volunteers (Steinberg et al., 2008). Importantly, female impulsiveness did not affect utilitarian behavior. Females displayed higher scores of empathy, and specifically of empathetic concern and personal distress as compared to males. Empathetic concern reflects the emotional reactions of apprehension and compassion induced by observing someone else in a condition of pain or need (e.g., Batson, 2010). Personal distress is an aversive emotional reaction that takes place in an individual when experiencing in a vicarious manner another's affective state (Eisenberg et al., 2010). Both traits are indices of the individual disposition to be emotionally influenced by the perception of the affective condition of others.

Empathy plays an important role in social contexts, as it fuels the motivation to increase others' welfare and favors pro-social behavior (e.g., Penner et al., 2005). In females, contrary to males, the consideration of the condition of the other, fostered by empathetic skills, likely exerted an inhibitory effect on their engagement in action and judgment of moral acceptability. 


\section{Limitations of the study}

Using a script-driven mental imagery paradigm based on moral dilemmas to investigate ethical decision-making may represent a limitation for the extensibility of the present results to real-life situations (e.g. Bauman, et al., 2014). Nevertheless, paradigms based on script-driven mental imagery have been largely employed and have proven effective for the study of emotional and cognitive processes that, due to technical and/or ethical constrains cannot be addressed in a naturalistic fashion (see for instance the study by Ricciardi et al., 2013 that addressed forgiveness and the study by Pietrini et al., 2000, which investigated unrestrained aggressiveness). Here, the study of moral decisionmaking in naturalistic settings would have required volunteers to be exposed to serious life threats that is, conditions that would neither be ethically acceptable nor feasible. Paradigms based on imagery, also, allow for controlling for multiple intervening factors that may act as potential confounds in reallife situations. In our study, dilemmas meant to elicit great emotional involvement, such as the ones that required participants to imagine that their own survival was at stake, indeed, were rated as more arousing. As arousal is a physiological correlate of action (see for example Teper et al., 2011), this result indicates that volunteers effectively engaged in mental imagery and experienced emotional involvement during moral decision-making.

\section{Conclusion}

The results of the present study indicate that the moral compass in males is strongly influenced by venturesomeness, which facilitates the engagement in action. Thus, in this gender, "utilitarian" responses may reflect reduced harm aversion. Conversely, in females, moral action and evaluation are influenced by empathetic capacities only.

Future research may target female sub-groups that exhibit high sensation-seeking behavior, such as individuals with borderline personality disorder or drug addict patients, to shed further light on the differential role that both gender and personality traits play in moral decision-making, as well as in judgments of ethical acceptability.

\section{Acknowledgments}

The authors are thankful to the undergraduate students who helped in the acquisition of data: Gaia Marchetti, Roberta Di Pasquale and Francesca Vacca.

\section{References}

Aluja A., Torrubia R. Hostility-aggressiveness, sensation seeking, and sex hormones in men: re-exploring their relationship. Neuropsychobiology, 50(1): 102-7, 2004.

American Psychiatric Association. Diagnostic and Statistical Manual of Mental Disorders, Fifth Edition. 2013, Arlington, VA: American Psychiatric Association.

Batson C.D. Empathy-induced altruistic motivation. pp. 15-34. In: Mikulincer M., Shaver P.R. Eds. Prosocial motives, emotions, and behaviors: The better angels of our nature. Washington, DC, American Psychological Association, 2010.

Beattie G. Sex differences in driving and insurance risk: Understanding the neurobiological and evolutionary foundations of the differences. 2008, Manchester, England: University of Manchester.

Bentham J. An introduction to the principles of morals and legislation. pp. 7-398. Utilitarianism. 1789/1961, Garden City, NY: Doubleday.

Bradley M.M., Lang P.J. Measuring emotion: the Self-Assessment Manikin and the Semantic Differential. Journal of Behavior Therapy and Experimental Psychiatry, 25(1):49-59, 1994.

Bauman C.W., McGraw A.P., Bartels D.M., Warren C. (2014). Revisiting External Validity: Concerns about Trolley Problems and Other Sacrificial Dilemmas in Moral Psychology. Social and Personality Psychology Compass 8/9, 536-554, 10.1111/spc3.12131.

Coccaro E.F., Lee R., McCloskey M., Csernansky J.G., Wang L. Morphometric analysis of amygdala and hippocampus shape in impulsively aggressive and healthy control subjects. Journal of psychiatric research, 69: 80-6, 2015.

Cross C.P., Cyrenne D.L., Brown G.R. Sex differences in sensation-seeking: a meta-analysis. Scientific Reports, 3:2486, 2013.

Davis M.H. A multidimensional approach to individual differences in empathy. JSAS Catalog of Selected Documents in Psychology, 10: 85, 1980.

Eisenberg N., Eggum N.D., Di Giunta L. Empathyrelated Responding: Associations with Prosocial Behavior, Aggression, and Intergroup Relations. Social issues and policy review, 4(1): 143-180, 2010. 
Eysenck S.B.G., \& Eysenck H.J. Impulsiveness and venturesomeness: Their position in a dimensional system of personality description. Psychological Reports, 43(3): 1247-1255, 1978.

Fumagalli M., Ferrucci R., Mameli F., Marceglia S., Mrakic-Sposta S., Zago S., Lucchiari C., Consonni D., Nordio F., Pravettoni G., Cappa S., Priori A. Gender-related differences in moral judgments. Cognitive processing, 11(3): 219-26, 2010.

Greene J.D., Morelli S.A., Lowenberg K., Nystrom L.E., Cohen J.D. Cognitive load selectively interferes with utilitarian moral judgment. Cognition, 107(3): 1144-54, 2008.

Iofrida, C., Palumbo, S., Pellegrini, S. (2014). Molecular genetics and antisocial behavior: where do we stand? Exp Biol Med, 239(11): 1514-23.

Kahane G., Everett J.A., Earp B.D., Farias M., Savulescu J. 'Utilitarian' judgments in sacrificial moral dilemmas do not reflect impartial concern for the greater good. Cognition, 134: 193-209, 2015.

Lotto L., Manfrinati A., Sarlo M. A new set of moral dilemmas: norms for moral acceptability, decision times, and emotional salience. Journal of Behavioral Decision Making, 27: 57-65, 2014.

McNair D.M. Lorr M., Droppleman L.F. Manual for the Profile of Mood States. 1971. San Diego, CA: Educational and Industrial Testing Services.

Moeller F.G., Barratt E.S., Dougherty D.M., Schmitz J.M., and Swann A.C. Psychiatric aspects of impulsivity. American Journal of Psychiatry, 158(8): 1783-93, 2001.

Morgan J.E., Gray N.S., Snowdena R.J. The relationship between psychopathy and impulsivity: A multi-impulsivity measurement approach. Personality and Individual Differences, 51(4): 429-34, 2011.

Moore A.B., Clark B.A., Kane M.J. Who shalt not kill? Individual differences in working memory capacity, executive control, and moral judgment. Psychological Science, 19(6): 549-57, 2008.

Monterosso J., Ainslie G. Beyond discounting: possible experimental models of impulse control. Psychopharmacology (Berl), 146: 339-47, 1999.

Pampel F.C. Gender equality and the sex differential in mortality from accidents in high income nations. Population Research and Policy Review, 20: $397-$ 421, 2001.

Penner L.A., Dovidio J.F., Piliavin J.A., Schroeder D.A. Prosocial behavior: Multilevel perspectives. Annual Review of Psychology, 56: 365-92, 2005.
Pietrini P., Guazzelli M., Basso G., Jaffe K., Grafman J. Neural correlates of imaginal aggressive behavior assessed by positron emission tomography in healthy subjects. Am J Psychiatry, 157(11): 1772-81, 2000.

Pietrini P., Bambini V. Homo ferox: The contribution of functional brain studies to understanding the neural bases of aggressive and criminal behavior. International journal of law and psychiatry, 32(4): 259-65, 2009.

Ricciardi E., Rota G., Sani L., Gentili C., Gaglianese A., Guazzelli M., Pietrini P. How the brain heals emotional wounds: the functional neuroanatomy of forgiveness. Front Hum Neurosci, 7: 839, 2013.

Rigoni, D., Pellegrini, S., Mariotti, V., Cozza, A., Mechelli, A., Ferrara, S.D., Pietrini, P., Sartori, G. (2010). How neuroscience and behavioral genetics improve psychiatric assessment: report on a violent murder case. Front Behav Neurosci, 4: 160.

Russo P.M., Leone L., De Pascalis V. Cross-cultural validity of the I7 impulsiveness-venturesomenessempathy scales: evidence from the Italian I7. Comprehensive psychiatry, 52(4): 446-52, 2011.

Sartori, G., Pellegrini, S., Mechelli, A. (2011). Forensic neurosciences: from basic research to applications and pitfalls. Curr Opin Neurol, 24(4): 371-7.

Scarpa A., Raine A. Psychophysiology of anger and violent behavior. Psychiatric Clinics of North America, 20(2): 375-94. 1997.

Scheele D., Striepens N., Kendrick K.M., Schwering C., Noelle J., Wille A., Schläpfer T.E., Maier W., Hurlemann R. Opposing effects of oxytocin on moral judgment in males and females. Human Brain Mapping, 35(12): 6067-76, 2014.

Steinberg L., Albert D., Cauffman E., Banich M., Graham S., Woolard J. Age differences in sensation seeking and impulsivity as indexed by behavior and self-report: evidence for a dual systems model. Developmental psychology, 44(6): 1764-78, 2008.

Teper R., Inzlicht M., Page-Gould E. Are we more moral than we think? Exploring the role of affect in moral behavior and moral forecasting. Psychological Science, 22(4), 553-8, 2011.

Zhao J., Macdonald S., Borges G., Joordens C., Stockwell T., Ye Y. The rate ratio of injury and aggressive incident for alcohol alone, cocaine alone and simultaneous use before the event: a case-crossover study. Accident; analysis and prevention, 75: 137-43, 2015.

Zuckerman M. Sensation seeking and risky behavior. pp. 51-72. 2007. Washington, DC: American Psychological Association. 